\title{
Oral Health Status, Knowledge, and Practices in an Amish Population
}

\author{
Robert A. Bagramian, DDS, DrPH \\ Chairman \\ Sena Narendran, BDS, DDPH, MSc

\section{A. Mahyar Khavari} \\ Department of Prevention and Health Care \\ School of Dentistry \\ University of Michigan \\ Ann Arbor, Ml 48109-1078
}

\begin{abstract}
This study was conducted in the summer of 1985 to assess the oral health status, knowledge, and practices of an Amish population in southwest Michigan. Dental caries experience, periodontal health, and oral hygiene status were recorded using decayed, missing, and filled surfaces (DMFS), periodontal index (PI), and simplified oral hygiene index (OHI-S). Data on oral health knowledge and practices were collected by interviews using a structured questionnaire. Results showed significantly lower levels of disease among Amish. DMFS scores for 5-17-year-old Amish children were almost half that of the US general population (NIDR 1979-80). PI score of all ages combined was 2.0 , which was 3.6 times lower than a national sample (1971-74). Lower levels of disease in Amish could be related to their way of life and dietary patterns. A relatively higher level of unmet need for prosthodontic care, inadequate oral health knowledge, and barriers to dental care in the study population emphasize the need for dental public health and health education programs.
\end{abstract}

Key Words: Amish, caries, periodontal disease, oral hygiene, oral health knowledge, oral health practices

The oral health of numerous contemporary and indigenous populations has been studied in different nations (1-11). These studies were both anthropological (1-3) and epidemiologic (4-11) in nature. In the United States, national surveys done periodically have documented the oral health of American citizens (11-13). Further, in the US the oral health of a group of native Americans, the Pima Indians, has been investigated recently (14-15). There is a lack of documentation of oral health status of the Amish population, which differs from the general population primarily in its life-style and dietary habits. Amish are a group of settlers from

Send correspondence and reprint requests to Dr. Bagramian. This paper was presented at the American Association for Dental Research annual meeting, March 12-15, 1986, Washington, DC. Manuscript received: $5 / 8 / 87$; returned to authors for revision: $6 / 11 / 87$; accepted for publication: $4 / 18 / 88$. northern Europe who first arrived in the United States during the latter half of the 18 th century (16).

In the US, the Old Order Amish number over 75,000 persons. Over 80 percent of the Amish population live in Pennsylvania, Ohio, and Indiana; more than 50 percent of these live in the counties of Lancaster (Pennsylvania), Holmes (Ohio), and Lagrange-Elkhart (Indiana) (17). The Amish settlement in southwestern Michigan constitutes approximately 2,000 people originally from northern Indiana. The Amish life-style is dependent on farmland; settlers moved from Indiana to Michigan in the late 1970 s in search of more available land at cheaper cost.

The unit of an Amish society is the church district, which is determined by the number of people who can be accommodated in a farmhouse for religious services and how far one can travel conveniently by horse and buggy to attend. The districts are ruled over by lay clergy called bishops who are chosen by lot (17). The present investigation appears to be the first oral health study of this group (18-19).

The association between diet and dental caries has been well documented (20-22). The Amish have a unique life-style, generally abstaining from processed food items, and relying on homegrown foods. Since as much as 80 percent or more of the sugar consumed in developed countries is in hidden form (23), it could be suggested that dietary habits of Amish might have a beneficial effect on their dental health.

The purpose of this study was to assess (1) the oral health status of a selected Amish population, (2) their knowledge and attitude to oral health, and (3) their dental health behavior.

\section{Methods}

The study population was composed of 121 subjects from 21 Amish families living in southwest Michigan. The local bishop was contacted concerning participation in the study. Initially 26 families were contacted, of whom $21(81 \%)$ agreed to be included in the study. The families contacted for the study were those within one church district in southwestern Michigan. Of the 21 families that consented, all of the members present at the time of examination agreed to participate in the 
study. This sample may not be representative of the Amish population due to the small numbers of participants in the study and potential selection bias.

There were 68 subjects younger than 17 years of age with 37 males and 31 females, and 53 older than 17 years of age including 25 males and 28 females. Dental examinations included caries experience, oral hygiene status, and periodontal health and were carried out in the summer of 1985 by an oral epidemiologist with the help of an experienced recorder. Dental examinations were conducted in natural light with subjects seated on a straight-back chair using a mouth mirror and No. 17 explorer.

Diagnostic criteria for dental caries were the same as those used by the National Institute of Dental Research, NIDR (11). Softness or definite break in continuity of enamel was a prerequisite for a tooth to be considered carious. Each tooth space was recorded only once. The reason for a missing tooth, either because of caries or for any other reason, was assigned by the examiner based on the caries experience of the respective subject. Wherever necessary, teeth were probed to confirm the presence or absence of dental caries. Radiographs were not used. Caries experience of each subject was recorded using decayed, missing, and filled surfaces (DMFS).

Periodontal disease status was assessed by applying the periodontal index (PI) of Russell (24), with criteria based on signs of periodontal inflammation, pocket formation, and loss of function. Each tooth in the mouth was scored; scores were totaled and then divided by number of teeth present. This mean score represents the periodontal condition of the teeth in the mouth. The PI was used in this study to allow comparisons with existing national and international data. The mesiobuccal area of every permanent tooth was examined for periodontal pockets using a modified probe, which has a $2 \mathrm{~mm}$ black band around the shank starting at $4 \mathrm{~mm}$ from the tip and ending at $6 \mathrm{~mm}$ from the tip. A score of four was given if the metal tip was no longer visible when the probe was inserted to the depth of the pocket and the black band remained visible. A score of six was given if both metal tip and the black band was submerged in the pocket.

The simplified oral hygiene index (OHI-S) was applied to measure oral hygiene status (25). OHI-S has two component parts, debris and calculus, each having a range of scores from zero to three. Six representative surfaces were scored in each mouth and a mean was derived for each person by dividing the total scores by six.

Data on oral health knowledge and practices were collected by face-to-face interviews. A survey instrument was developed and pretested among family members of the Amish bishop $(n=7)$. The questionnaire included 25 questions, four open-ended and 21 precoded. The responses to open-ended questions were coded before the statistical analyses. The number of choices to precoded questions ranged from two to eight. Forty-eight percent of the questionnaires were related to oral health knowledge, 44 percent to dental health practices, and 8 percent to general items of inter- est such as sources of drinking water. The average time for the interviews was 18 minutes, with a range of 12 to 27 minutes.

\section{Results}

Dental Caries. Caries experience ranged from 1.92 DMFS for children under 11 years to 34.61 for adults over 35 years (Table 1 ). Approximately 25 percent of the population under 17 years was caries-free. Distribution of DMFS scores was not normal as indicated by relatively higher standard deviations. The finding of a higher standard deviation (compared to the mean) is often encountered in many epidemiologic studies following the recent decline in dental caries in children. The distribution of DMFS scores by age and sex showed females with higher scores than males in all groups except 18-24 years. Analysis by age group indicated that, with increasing age, contribution from decayed surfaces (D) to DMFS scores remained constant, while those from missing (M) and filled surfaces (F) increased.

Relative contributions of decayed (D), missing (M), and filled (F) to DMFS scores are shown in Table 2. The ratio of decayed D to DMF surfaces was 5.4 percent, indicating very little unmet needs of dental caries in this population. The MS/DMFS ratio of 46.5 percent reflects a high missing component, and also a high level of unmet need for prosthodontic care. The FS/DMFS ratio for the 5-17-year-old age group in the study population was 62.6 percent.

Oral Hygiene Status. Oral hygiene scores ranged from 0.93 in children under 11 to 1.72 in adults over 35 years. The OHI-S scores shown in Table 3 indicate a higher score for males compared to the females. There appears to be a typical decline in OHI-S scores around the time of puberty for both sexes followed by an increase in scores after age 25.

TABLE 1

Caries Experience (DMFS) by Age

\begin{tabular}{lcc}
\hline Age & $N$ & DMFS \pm SD \\
\hline$<11$ & 49 & $1.92 \pm 3.99$ \\
$12-17$ & 19 & $3.79 \pm 4.83$ \\
$18-24$ & 16 & $9.38 \pm 6.99$ \\
$25-34$ & 14 & $15.79 \pm 8.18$ \\
$35+$ & 23 & $34.61 \pm 19.33$ \\
\hline
\end{tabular}

TABLE 2

Ratios of Decayed, Missing, and Filled Surfaces to DMFS

\begin{tabular}{lcc}
\hline $\begin{array}{l}\text { Status of } \\
\text { Surface }\end{array}$ & Mean \pm SD & Ratio \\
\hline D & $0.60 \pm 1.23$ & DS/DMFS $(\times 100)=5.4 \%$ \\
F & $5.29 \pm 6.77$ & FS/DMFS $(\times 100)=48.1 \%$ \\
M & $5.12 \pm 11.19$ & MS/DMFS $(\times 100)=46.5 \%$ \\
DMF & $11.02 \pm 15.60$ & - \\
\hline
\end{tabular}


TABLE 3

Mean OHI-S Scores by Age and Sex

\begin{tabular}{lrlrll}
\hline & \multicolumn{3}{l}{ Males } & & \multicolumn{2}{l}{ Females } \\
\cline { 2 - 3 } \cline { 5 - 6 } Age (yrs) & $n$ & OHI-S \pm SD & & $n$ & OHI-S \pm SD \\
\hline$<11$ & 5 & $0.93 \pm 0.66$ & & 5 & $0.93 \pm 0.15$ \\
$12-17$ & 12 & $0.93 \pm 0.74$ & & 7 & $0.81 \pm 0.38$ \\
$18-24$ & 7 & $0.81 \pm 0.39$ & & 9 & $0.72 \pm 0.56$ \\
$25-34$ & 8 & $1.48 \pm 0.85$ & & 6 & $0.75 \pm 0.76$ \\
$35+$ & 10 & $1.72 \pm 0.51$ & & 13 & $1.00 \pm 0.92$ \\
\hline
\end{tabular}

TABLE 4

Mean PI Scores by Age and Sex

\begin{tabular}{|c|c|c|c|c|}
\hline \multirow[b]{2}{*}{ Age (yrs) } & \multicolumn{2}{|r|}{ Males } & \multicolumn{2}{|c|}{ Females } \\
\hline & $n$ & $\mathrm{PI} \pm \mathrm{SD}$ & $n$ & $\mathrm{PI} \pm \mathrm{SD}$ \\
\hline$<11$ & 5 & $0.05 \pm 0.11$ & 5 & $0.11 \pm 0.17$ \\
\hline $12-17$ & 12 & $0.24 \pm 0.22$ & 7 & $0.09 \pm 0.09$ \\
\hline $18-24$ & 7 & $0.31 \pm 0.30$ & 9 & $0.03 \pm 0.06$ \\
\hline $25-34$ & 8 & $0.23 \pm 0.20$ & 6 & $0.26 \pm 0.33$ \\
\hline $35+$ & 10 & $0.36 \pm 0.47$ & 13 & $0.26 \pm 0.16$ \\
\hline
\end{tabular}

Periodontal Health. Periodontal index scores for this population were consistently low, as shown in Table 4. Periodontal index scores increased with age from a low of 0.05 for children under 11 years of age to 0.36 for adults over 35 . As with OHI-S scores, males generally had a higher PI than females. Of the 53 adults examined for periodontal pockets using a specially marked probe, only two subjects had periodontal pockets. One subject had two $4 \mathrm{~mm}$ pockets and the other had two pockets that were more than $5 \mathrm{~mm}$ deep. Both subjects were over 35 years of age.

Dental Health Behavior. Almost two-thirds of this Amish population reported brushing their teeth less than once a day, while only 1.3 percent brushed twice or more a day; 2.6 percent reported never having brushed their teeth.

Knowledge. In general, respondents exhibited inadequate knowledge of the available preventive methods for dental diseases. An open-ended question on prevention of periodontal diseases showed that 73 percent of respondents were unaware of any preventive practices for controlling periodontal disease. To a precoded question on prevention of dental caries, 55 percent agreed that fluoride is helpful in preventing tooth decay, while 26 percent did not know the beneficial role of fluoride. Almost all who agreed on the cariostatic role of fluoride, however, obtained this information from their dentists.

Treatment Needs. The majority $(61 \%)$ of the Amish in this study perceived themselves as possessing good dental health. Only 7 percent believed their teeth were in poor condition. About one-third of the population did not perceive themselves as having good dental health status and felt the need for dental treatment.
Dental Visits. The study population appeared to consist mostly of irregular dental attenders. Among the respondents, more than one-third (35\%) reported visiting a dentist every six months to one year, 19 percent visited every 12 to 24 months, and 46 percent visited less frequently than every two years. In other words, nearly half of the study population was made up of irregular attenders of dental care.

Financial barriers seemed to be the most important factor for Amish not seeking dental care regularly. About 55 percent of the respondents felt dental services were expensive, 8 percent cited pain as a barrier to their being regular attenders, and availability of dental services was a problem for 6 percent. About one-third (31 percent) did not perceive themselves as needing dental care.

\section{Discussion}

Given the poor oral hygiene status and lack of adequate knowledge concerning dental health and practices, as well as existing barriers to seeking dental care, it was surprising that levels of dental diseases were so low in the Amish population. Such low levels of dental diseases could be explained by their dietary habits and possibly herd immunity (collective resistance to the diseases displayed by the community).

A comparison of dental caries experience between the Amish and US children aged 5-17 $(11,12)$ indicated DMFS scores of Amish children to be approximately one-half to one-third of non-Amish. Amish children in the present study had a DMFS score of 2.4 , while nonAmish children of similar age groups had DMFS values of 7.1 in 1971-73 and 4.8 in 1979-80 $(11,12)$. Some of the differences between the Amish and non-Amish may be explained by the secular decline in dental caries first evident in 1979-80 and probably continuing during the 1980s.

Low levels of dental caries found in Amish children could be attributed to infrequent snacking habits and consumption of sugar only at meal times. The latter concept is in agreement with the landmark Vipeholm study (20) on the association of sugar and dental caries. Amish homes do not have the usual food products such as prepared, precooked, frozen, and baked products that can be purchased in supermarkets. Although these families reported eating three large meals per day including dessert containing a large amount of sugar, they are not in the habit of constantly snacking between meals, like the general public. Analysis of well water revealed a low fluoride level, thus ruling out fluoride as a factor in low levels of dental caries seen in the population.

The Amish do not purchase any type of health insurance plan, including dental insurance (16). Since their population consists primarily of irregular dental attenders, a high D/DMFS ratio, indicating unmet restorative needs, was expected in Amish children. On the contrary, the D/DMFS ratio was only 5 percent and the DMFS scores were mainly made up of missing $(M)$ and filled (F) components. The F/DMFS ratio for 5-17-yearolds in this study was 62.6 percent, compared to 80.3 
percent in non-Amish children from NIDR Region III (12). Factors such as financial barriers, lack of dental insurance, and availability of dental services might have contributed to the difference in the filled surface (FS) component of DMFS between these two groups.

The low level of treatment needs for dental caries in the study population should be interpreted cautiously. This low D/DMFS ratio may be due to a selection bias in the sample, with the dentally conscious Amish more likely to have consented to participate in the study. The high $\mathrm{M}$ component could also have contributed to the low D/DMFS ratio. A study on a larger scale is needed before this finding of low D/DMFS ratio can be generalized to the entire Amish population.

The relatively high M/DMFS ratio is similar to that of the New Zealand population that participated in the International Collaborative Study (8). The Amish, like New Zealanders, are predominantly farmers and face certain barriers to seeking dental care. They may be reluctant to invest their time in traveling, waiting, and receiving treatment. Also restorative care would involve follow-up visits for completion and replacement of restorations. Along with the time factor, financial barriers and a lack of availability of dental services might have contributed to the relatively high M/DMFS ratio. A high $\mathrm{M}$ component and edentulousness appear to be the social norm among New Zealanders, as seen in the International Collaborative Study. We are not certain whether the Amish possess similar social and cultural values; thus, there is a need for further research on sociological and cultural aspects of the Amish population.

\section{"Although these families reported eating three large meals per day, including dessert containing a large amount of sugar, they are not in the habit of constantly snacking between meals, like the general public."}

OHI-S scores of the Amish were higher than those of the non-Amish who participated in the NCHS survey of 1971-74. In addition, Caucasians aged 6-76 (1971-74) had 3.6 times (0.76 vs 0.21 ) higher mean PI scores than this study population (26). The high OHI-S and low PI scores suggest that certain features in the oral flora as well as the immune system of the Amish may be responsible for their being less susceptible to periodontal diseases. The oral flora of the Amish should be a subject of further research. The finding that females in general have better oral hygiene and periodontal health status than males is not unique to this study. The small sample size in the present study warrants caution in generalizing to the rest of the Amish population the finding of better oral hygiene and periodontal health in the Amish females than males.
The lack of knowledge and attitudes concerning dental health can be attributed to the low level of literacy of the Amish. The Amish do not encourage education of their children, who only attend their own schools to the eighth grade. In addition, without electricity and telephones, there is relatively little communication with the outside world. The Amish have limited contact with the media since they do not possess radios or televisions. This study showed a high level of unmet need for prosthodontic care in the Amish population. Nearly one-half of those who participated in the study were reported to be irregular attenders of dental care. All these factors indicate that an urgent need for dental public health programs - preventive, curative, and educational-for this population.

This study is unique in that there has apparently been no documentation of dental health status in the Amish previously. This is due primarily to the life-style of the Amish, who are reluctant to have contact with groups other than themselves and do not easily consent to participate in any study. Members of the Amish community do not wish to have their life-styles threatened by contact with the outside world. This is part of the basis for not having modern conveniences such as electricity, radio, and TV. Access to the population was very difficult and required contact and discussions with the designated bishop of the community.

Limitations of this study include small numbers of subjects and selection bias, which indicate the sample may not be representative. The conditions under which dental examinations were conducted limited the use of certain dental indices. Biases might also have been introduced by refusals and "non-contact" prior to the study as well as during the interviews. The lack of representativeness of the study population is often a limitation in such studies. A representative sample would entail not only a large investment of resources, but also cooperation of subjects, which may not be possible in a detached community such as the Amish.

\section{References}

l. Leigh RW. Dental pathology of Indian tribes of varied environmental and food conditions. Am J Phys Anthropol 1925;8:179-99.

2. Stewart TD. Dental caries in Peruvian skulls. Am J l'hys Anthropol 1931;15:315-25.

3. Hardwick JL. The incidence and distribution of carie's throughout the ages in relation to an Englishman's diet. Br Dent I 1960;108:9-17.

4. Mehta FS, Shroff BC. Aspects of dental diseases in the Indian aborigines. Int Dent J 1965;15:182-9.

5. Russell AL. World epidemiology and oral health. In: Kreshover SJ, McClure JF (eds). Environmental variables in oral disease. I'ub no 81. Washington, DC: American Assuciation for the Advancement of Science, 1966.

6. Schamschula RG, Barmes DE, Keyes PH, Gulbinat W. Prevalence and interrelationship of root caries in Lufa, Papua New Guinea. Community Dent Oral Epidemiol 1974;2:295-304

7. Donnelly CJ, Thomson LA, Stiles HM, Brewer C, Neel JV, Brunelle JA. Plaque, caries, periodontal diseases, and acculturation among Yanomamo Indians, Venezuela. Community Dent Oral Epidemiol 1977;5:30-9.

8. Cohen LK. Dental care delivery in seven nations. International collaborative study and dental manpower systems in relation to oral health status. In: Ingle JJ, Blair P (eds). International dental care delivery systems. Battle Creek, MI: WK Kellogg Foundation, 1978. 
9. Todd JE, Walker AM, Dodd P. Adult dental health. Vol 2. United Kingdom 1978. London: HMSO 1982.

10. Nordling $\mathrm{H}$, Tala $\mathrm{H}$. Oral health in Finland. Helsinki: National Board of Health, 1982.

11. Harvey CR, Kelley JE (eds), US Public Health Service, National Center for Health Statistics. Statistics: decayed, missing and filled teeth among persons 1-74 years, United States 1971-74. DHHS pub no (PHS) 79-1222. Washington, DC: Government Printing Office, 1979

12. US Department of Health and Human Services. The prevalence of dental caries in United States children. National Dental Caries Prevalence Survey. NIH pub no (NIH) 82-2245. Washington, DC: Government Printing Office, 1981.

13. Löe H, Carlos JP. Survey results previewed. J Am Dent Assoc 1987:114-130.

14. Shlossman M, Knowler D, Pettitt A, Arevalo, Genco RJ. Type Il diabetes and periodontal Disease [Abstract]. J Dent Res 1987;66(Spec Iss):256.

15. Genco RJ, Shlossman M, Zambon JJ. Immunologic studies of periodontitis patients with type II diabetes mellitus [Abstract]. J Dent Res 1987;66(Spec Iss):257.

16. Hostetler JA. Amish society. 3rd ed. Baltimore, MD: Johns Hopkins University Press, 1980.

17. McKusick VA. The Amish. Endeavor 1980;4:52-7.
18. Bagramian RA, Khavari AM, Narendran S. Oral health assessment in a selected Amish population [Abstract]. J Dent Res 1986;65(Spec Iss): 171

19. Bagramian RA, Khavari AM, Ward M. Correlation of dental caries and $\mathrm{S}$ mutans in a rural Amish population [Abstract]. J Dent Res 1987;66(Spec Iss):327.

20. Gustafsson BE, Quensel CE, Lanke LS, et al. The Vipeholm dental caries study. The effects of different levels of carbohydrate intake on caries activity in $\mathbf{4 3 6}$ individuals observed for five years. Acta Odont Scand 1956;11:232-364.

21. Takeuchi M. Epidemiological study on dental caries in Japanese children before, during, and after World War II. Int Dent ] 1961;11:443-57.

22. Harris R. Biology of the children of Hopewood House, Bowral, Australia, 4. Observations on dental caries experience extending over five years (1957-61). J Dent Res 1963;62:1387-99.

23. Viton $A$. The outlook for sugar and sugar-containing foods. FO Licht's Int Sugar Rep 1983;115:147-55.

24. Russell AL. A system of classification and scoring for prevalence surveys of periodontal disease. J Dent Re's 1956;35:350-9.

25. Greene JC, Vermillion JR. The simplified oral hygiene index. J Am Dent Assoc 1964;68:7-13.

26. Kelly JE, Harvey CR. Basic data on dental examination findings of persons 1-75 years, United States, 1971-1974. DHEW pub no (PHS)79-1662, series 11, no 214. 